Illinois State University

ISU ReD: Research and eData

Theses and Dissertations

9-29-2017

\title{
Scheduling Recess: Perceptions Of Lunchroom Supervisors, Teachers, And Principal
}

Reilly Layne McKinnis

Illinois State University, krmcki1@ilstu.edu

Follow this and additional works at: https://ir.library.illinoisstate.edu/etd

Part of the Human and Clinical Nutrition Commons

\section{Recommended Citation}

McKinnis, Reilly Layne, "Scheduling Recess: Perceptions Of Lunchroom Supervisors, Teachers, And Principal" (2017). Theses and Dissertations. 873.

https://ir.library.illinoisstate.edu/etd/873

This Thesis is brought to you for free and open access by ISU ReD: Research and eData. It has been accepted for inclusion in Theses and Dissertations by an authorized administrator of ISU ReD: Research and eData. For more information, please contact ISUReD@ilstu.edu. 
SCHEDULING RECESS: PERCEPTIONS OF LUNCHROOM SUPERVISORS, TEACHERS, AND PRINCIPAL

Reilly L. McKinnis

56 Pages

Purpose

The purpose of this study was to ascertain the perceptions of elementary school staff in regards to scheduling recess after or before lunch and the effect each schedule had on students. Methods

This research was conducted in Fall 2016 when a Midwestern elementary school had recess after lunch (RAL) and in Spring 2017 when the same school had recess before lunch (RBL). A mixed methods approach was used. Nineteen teachers completed a Likert-scale survey, six of whom completed both the pre- and post-survey. One principal and five lunchroom supervisors participated in individual semi-structured interviews pertaining to their perceptions

of recess scheduling. Descriptive statistics were calculated for all surveys. Dependent paired ttest were conducted on pre- and post-surveys. Qualitative data analysis utilized the constant comparison method, which is part of Grounded Theory.

\section{Results}

The key finding from this study was that logistical planning needs to be a priority of policy makers. School professionals should be clearly informed about the changes being made, how any changes may affect their job directly or indirectly, and provided adequate training to allow every school professional the best opportunity to contribute to a successful schedule 
change. Issues that pertained to logistical planning typically were perceived to be less adequate after RBL was implemented. However, issues regarding the academics and behavior of children were typically perceived as more beneficial after RBL was implemented. These results suggest that RBL does produce perceived positive benefits from school professionals, but detailed planning, preparation, and logistical barriers should be anticipated and resolved before implementation of RBL.

\section{Applications to Child Nutrition Professionals}

The results of this study may be useful for school administrators and other school staff including principals, teachers, and lunchroom supervisors considering changing schedules from a RAL to RBL format. Professionals should have a clear plan of action before implementing a RBL schedule. Challenges and achievements expressed by professionals who have already undergone the change are invaluable for this plan of action.

KEYWORDS: School professionals, Recess timing, Recess before lunch, Elementary, Policy makers, Students 
SCHEDULING RECESS: PERCEPTIONS OF LUNCHROOM SUPERVISORS, TEACHERS, AND PRINCIPAL

REILLY L. MCKINNIS

A Thesis Submitted in Partial Fulfillment of the Requirements for the Degree of

MASTER OF SCIENCE

Department of Family and Consumer Sciences

ILLINOIS STATE UNIVERSITY 
C 2018 Reilly L. McKinnis 
SCHEDULING RECESS: PERCEPTIONS OF LUNCHROOM SUPERVISORS, TEACHERS, AND PRINCIPAL

\author{
REILLY L. MCKINNIS
}

COMMITTEE MEMBERS:

Julie Schumacher, Chair

Jennifer Banning

Julie McCoy 


\section{ACKNOWLEDGMENTS}

I would like to thank the principal, teachers, and lunchroom supervisors at Bent Elementary School for all the feedback and participation they gave during this study. I would also like the thank Dr. Julie Schumacher, Dr. Jennifer Banning, and Julie McCoy for all the advice, feedback, and mentoring you gave to me over the course of this research. I would have been lost without you. Finally, thank you to the Illinois State University Graduate School for allowing me to complete this research.

R. L. M. 


\section{CONTENTS}

Page

ACKNOWLEDGMENTS

$\begin{array}{ll}\text { CONTENTS } & \text { ii }\end{array}$

TABLES

CHAPTER I: LITERATURE REVIEW

Introduction 1

Methodology $\quad 5$

$\begin{array}{ll}\text { Quantitative Data Collection: Teachers } & 6\end{array}$

Qualitative Data Collection: Teachers $\quad 7$

Qualitative Data Collection: Principal $\quad 7$

Qualitative Data Collection: Lunchroom Supervisors $\quad 8$

Quantitative Data Analysis $\quad 8$

Qualitative Data Analysis $\quad 9$

Results and Discussion $\quad 9$

Quantitative Findings $\quad 9$

$\begin{array}{ll}\text { Qualitative Findings } & 14\end{array}$

$\begin{array}{ll}\text { Discussion } & 21\end{array}$

$\begin{array}{ll}\text { Conclusion and Application } & 28\end{array}$

CHAPTER II: EXTENDED LITERATURE REVIEW 32

National School Lunch Program $\quad 32$

Childhood Obesity Costs 33

$\begin{array}{ll}\text { Recess } & 36\end{array}$ 
Increased Lunch Time

$\begin{array}{ll}\text { Recess Before Lunch (RBL) } & 39\end{array}$

$\begin{array}{ll}\text { Conflicting Results } & 42\end{array}$

$\begin{array}{ll}\text { Perceptions of School Staff } & 44\end{array}$

$\begin{array}{lr}\text { REFERENCES } & 47\end{array}$

$\begin{array}{ll}\text { APPENDIX A: TEACHER SURVEY } & 52\end{array}$

APPENDIX B: PRINCIPAL AND LUNCHROOM SUPERVISORS INTERVIEW

QUESTIONS- RECESS AFTER LUNCH 55

APPENDIX C: PRINCIPAL AND LUNCHROOM SUPERVISORS INTERVIEW

QUESTIONS- RECESS BEFORE LUNCH

56 


\section{TABLES}

Table

Page

1. Mean Scores of Recess After Lunch and Recess Before Lunch Surveys

2. Comparing Select Interview Themes from Recess After Lunch to Recess Before Lunch

Interviews 


\section{CHAPTER I: LITATURE REVIEW}

\section{Introduction}

Since its inception in 1946, the National School Lunch Program (NSLP) and the United States Department of Agriculture: Food and Nutrition Service (USDA:FNS) have provided billions of lunches to poverty stricken students (USDA, 2017a). The NSLP is a federal government meal program that provides both free and reduced-priced lunches to students at participating schools (USDA, 2016). In 2016 alone, 30.4 million American students from lowincome families had access to a balanced meal because of the NSLP (USDA, 2017a). The meals schools serve must be 'nutritionally balanced' by meeting standards set by the USDA:FNS (USDA, 2016). These guidelines correspond to the USDA 2015-2020 Dietary Guidelines for Americans, which are supported by scientific evidence and put in place to help Americans follow a healthy diet and prevent chronic diet-related diseases to improve health. One preventable dietrelated condition that is affecting children in epidemic proportions is obesity (Daniels, 2006; Halpern et al., 2010).

There are over 12.7 million obese children and adolescents in the United States according to the Centers for Disease Control and Prevention (CDC) (2016). Children are now being affected by immediate and long-term obesity-related health conditions that previously only affected adults, which may lead to unhealthy adult lives and shorter life spans (Daniels, 2006; Halpern et al., 2010). Obesity in childhood not only results in medical consequences but psychological conditions as well (Sontag, Ali, Lehnert, Konnopka, Riedel-Heller, \& Konin, 2015). Battling this rise in childhood obesity and the chronic diseases that result, along with the economic, social, and monetary costs associated with obesity in children has been the source of much research (Bhatt, 2014; Daniels, 2006; Halpern et al, 2010; Sontag et al., 2015). Research 
has been conducted to estimate the cost of medical care and lost opportunity costs associated with children missing school due to obesity-related factors (Bhatt, 2014). Bhatt (2014) hypothesized that making student lunches just ten minutes longer, leading to a reduction in child obesity, would produce a cost savings of almost $\$ 33$ million in two years. It may also reduce national student absences by 700,000 days (Bhatt, 2014). These high costs associated with childhood obesity show an acute need to balance energy intake and expenditure in children. To reach large populations of children and combat childhood obesity, the ideal place to promote healthy behaviors is through the public educational system.

Recess during the school day is an important outlet that allows children to expend excess energy. However, the importance of recess for children is often overlooked or ignored, and many see no real reason to have recess in the school day, according to the International Play Association (IPA) (2014). Recess is vital to a child's development as it provides for social, emotional, cognitive, intellectual fulfillment, and, most importantly for this discussion, recess provides a means for children to expend excess energy (IPA, 2014).

There has been a recent movement and corresponding research which supports changing recess, which traditionally occurs after lunch, to before lunch (Bounds, Nettles, \& Johnson, 2009; Fenton, Rosen, Wakimoto, Patterson, Goldstein, \& Ritchie, 2015; Hunsberger, McGinnis, Smith, Beamer, \& O’Malley, 2014; Price \& Just, 2015, Strohbehn, Strohbehn, LanninghamFoster, Litchfield, Scheidel, \& Delger, 2016). Strohbehn et al., (2016) states that placing recess before lunch (RBL) leads to “....increased nutrient intake at lunch, decreased afternoon behavioral issues, and increased afternoon learning efficiency..." (p. 1). There are several other benefits to having RBL. Students typically waste less food (Strohbehn et al., 2016), make more nutritious food choices such as eating more fruits and vegetables (Price \& Just, 2015), and have 
better perceived classroom behavior (Hunsberger et al., 2014). This may be because students are not rushing to be "done" with their meal to have more time to play which results in increased feelings of hunger later in the day (Price \& Just, 2015). Despite these positive benefits for students, the CDC found that only $11 \%$ of elementary schools nationwide have a RBL policy in effect for all grades (CDC, 2015). There are some studies that have not found results supporting any benefits to having RBL. However, these studies typically only found insignificant results, conflicting results, or no change in eating behaviors of students (Cullen, Chen, Dave, \& Jensen, 2015; Fenton et al., 2015). These researchers suggest more research needs to be done to determine what factors influence student food preference and consumption.

Before deciding to make a change in schedule to RBL, a perspective from school professionals should be considered. Bounds et al. (2009) conducted a mixed methods study with teachers, principals, and school nutrition directors and found five points of concern from participants regarding the placement of recess, the most important being child feeding implications. Surveys and focus group discussions were both utilized (Bounds et al., 2009). Researchers found "barriers commonly identified by school professionals included preservation of instructional time, logistical issues such as addressing hand washing and winter clothing, and scheduling concerns" (p. 3) which may prevent schools from implementing RBL (Bounds et al., 2009). These barriers cover a wide variety of topics that need to be addressed. The study by Bounds et al., (2009) focused on perceptions of barriers in regards to implementing a program but did not evaluate perceptions or the positive outcomes that resulted after a policy change was actually implemented.

Another study conducted by Rainville, Wolf, and Carr (2006) utilized focus groups with school administrators, teachers, parents, and nutritional professionals to determine the most 
common barriers to implementing a RBL policy. Researchers used these focus groups to "refin[e] and finaliz[e] a series of questions designed to explore barriers to recess placement before lunch in elementary schools" (Rainville, et al., 2006). Administrators commented that the most common barriers to a RBL policy was loss of academic time, logistical complications, resistance to change (Rainville, et al., 2006). Teachers mentioned the same barriers but also thought that exercise, weather, and flexibility of administrators were also obstacles of a RBL policy (Rainville, et al., 2006). These researchers recommend future studies conduct pre- and post- schedule change studies to determine if positive changes result for the same group of students.

Even with these studies, several gaps in the literature exist regarding faculty and staff perceptions on RBL. More research is needed to determine the perceptions of faculty and staff about recess after lunch (RAL) versus RBL and their perceptions on the impact recess placement has on students when a policy change is actually implemented. This study will fill a gap in literature by assessing the pre- and post-perceptions that teachers, principals, and lunchroom supervisors have about RAL and RBL once a schedule change is implemented. The results of this study may be useful for school administrators and policy makers considering changing schedules from a RAL to RBL format. The results may also be of value for any professional concerned with the nutritional intake, behavior, or academic performance of students.

The purpose of this study was to identify the perceptions of elementary school staff in changing recess from after to before lunch and how this effects the students from the staff's point of view. This study included a principal, teachers, and lunchroom supervisors from an elementary public school in the Midwest before and after a schedule change from RAL to RBL. The independent variable was the schedule of recess in relation to lunch, either before or after. 
The dependent variable was the perceptions about this change and the effects on students from the perspective of school staff. School staff was defined as the principal, homeroom teachers, and lunchroom supervisors from the participating school. The elementary school participating in this study participates in the NSLP, which implies that all students have access to a nutritious and balanced lunch. This may help with behavior and attention problems after lunch related to hunger, if the child is actually eating what they are provided. This particular school provided an average of 363 students a free or reduced price lunch in the 2015-2016 school year. This study answered the following research questions: 1) What are the perceptions of the principal regarding the timing of recess and how it impacts the school? 2) What are the thoughts of lunchroom supervisors in regard to perceived food consumption before and after the schedule change? 3) What are the perceptions of teachers before and after the schedule change in regard to academic performance and behavior in the classroom? The following hypotheses were also made: 1) Teachers will rate classroom behavior lower when recess is after lunch and 2) Teachers will rate children's ability to focus higher when recess is before lunch.

\section{Methodology}

This research was conducted in fall 2016 and spring 2017. A mixed methods approach was used as suggested and supported by previous related research studies (Bounds et al., 2009; Hunsberger et al., 2014; Strohbehn et al., 2016). Broad categories of survey questions were drawn from Bounds et al. (2009). Researchers in the current study adapted questions for two interview sets from a series of questions that had already been pilot tested by Rainville et al. (2006).

Data was first collected in December 2016 when a local Midwestern elementary school had RAL for all grades, Kindergarten- $5^{\text {th }}$. In March 2017, data was collected again through the 
same interviews and surveys two and a half months after the school underwent a schedule change to RBL for all grades. Participants were drawn from a convenience sample of faculty and staff at the Kindergarten- $5^{\text {th }}$ grade elementary school under study. Inclusion criteria included the principal, homeroom teachers, and lunchroom supervisors who were at least 18 years of age and could read and speak English. Exclusion criteria were any faculty or staff that was not a principal, homeroom teacher, or lunchroom supervisor, under 18 years of age, or could not read or speak English. There were no exclusion criteria related to gender, race, or socioeconomic status. Only homeroom teachers were allowed to participate since these are the teachers that interact with students during the entire day and not just one period like art, physical education, or music elective teachers. Due to a low participation rate in the follow-up survey, a $\$ 25$ dollar gift card was offered as incentive and one participant was randomly selected to receive it. The Institutional Review Board at Illinois State University approved this study [995494-2]. Consent forms were administered, signed, and submitted electronically or returned in person by participants wishing to participate. A copy of the consent form was available to all participants.

\section{Quantitative Data Collection: Teachers}

Teacher contact information was obtained from the publically available email addresses posted on the Midwestern elementary school's website. The teachers were recruited by an email invitation with a link to an online survey. After reading a consent form and agreeing to participate, teachers were asked eight sets of questions to evaluate their perceptions of students' classroom behaviors and overall academic performance, as well as the logistics of the recess schedule and their personal preference as to when the students had recess. Five question sets were evaluated using a 5-point Likert-scale. A total of 19 homeroom teachers were invited to participate in this study. 
The same series of questions was asked the following March, two and a half months after the schedule change took place. Waiting until March allowed the students and staff to adjust to a new routine due to the changed recess time. As a result of waiting, perceptions of the change were likely more stable than if data had been collected sooner when challenges of a new schedule may have resulted in biased temporary perceptions. All homeroom teachers were asked to participate in the second round of surveys regardless of pre-survey participation. A list of complete questions asked may be found in Appendix A. At the end of both surveys, participants entered a unique identifier code so researchers could compare pre- and post- surveys but not identify the individual participant.

\section{Qualitative Data Collection: Teachers}

At the end of each survey, participants were asked three open-ended questions that allowed participants to share comments about both RAL and RBL. A list of these questions can be found in Appendix A. These questions allowed participants the opportunity to share thoughts and opinions which provided researchers a better understanding of participants' overall perceptions of each recess timing that was not captured by the quantitative closed-ended questions. Questions were analyzed using three levels of coding. Two researchers analyzed results separately and then compared major themes found.

\section{Qualitative Data Collection: Principal}

The principal of the school under study was recruited via email. After agreeing to participate and signing a consent form, the principal had an in-person interview at the school with two researchers. One researcher asked questions and took brief notes while the other listened and wrote detailed answers as verbatim as possible while the principal spoke. The principal was asked eight main questions and a series of follow-up and clarification questions. 
The questions regarded barriers to having both RAL and RBL, the impact recess placement has on the role of the principal, the students' behavior, and the principal's overall attitude towards each recess schedule. Eight similar questions were asked the following spring two and a half months after the students began RBL. The interview was conducted with the same two researchers so that notes were consistent. The list of questions asked can be found in Appendix B and $\mathrm{C}$.

\section{Qualitative Data Collection: Lunchroom Supervisors}

Researchers recruited lunchroom supervisors (LRS) in person at the school. The LRS were asked if researchers could interview them either that same day or the next day. Every LRS that was available agreed to participate in the pre-interview $(n=5)$. After signing a consent form, every LRS was asked the same eight main questions that the principal was asked along with follow up and clarification questions when needed during individual interviews. The same two researchers conducted the interviews and took notes as in the principal interview for consistency in reporting. The questions pertained to each LRS's perceptions about students' behavior in the cafeteria and on the playground, as well as each of their thoughts about recess timing. Eight similar questions were asked again after the change to RBL in a post-interview. Four of the same LRS participated in both interviews while one LRS only participated in the pre-interview and one only in the post-interview providing a total number of five participants in each interview set. The difference in participants was due to staffing turnover.

\section{Quantitative Data Analysis}

Survey data were analyzed using the statistical package SPSS Version 23.0 for Windows. Descriptive statistics calculated included mode, mean, standard deviations, and frequencies of total responses for all surveys. Pre- and post- surveys were analyzed separately. Cronbach's 
alpha was used to analyze the internal constancy of two related survey items. Identifier codes were used to match participants who completed both pre- and post- surveys. These surveys were reanalyzed separately using dependent paired $t$-tests. This allowed researchers to compare answers before and after the schedule change to develop a whole picture of the situation.

\section{Qualitative Data Analysis}

Separate semi-structured interviews were held with the school principle and five LRS. Qualitative data analysis utilized the constant comparison method, which is part of Grounded Theory. Two researchers coded the interview notes for main themes independently and then agreed upon key themes together during discussion. Coding used to analyze the data included open, axial, and selective coding. This allowed researchers to analyze several layers of the data and develop overarching themes among questions.

\section{Results and Discussion}

\section{Quantitative Findings}

Teacher survey. A total of 19 teachers received an online link to participate in a presurvey regarding their perceptions of RAL and RBL. The same 19 teachers received an online invitation to participate in a post-survey (RBL) the following spring. Thirteen surveys were completed in the fall for a participation rate of $68 \%$. One participant did not complete the entire survey but is included when an answer was provided. Eleven surveys were completed and returned in the spring. Two surveys were excluded from this study because they had identical identifier codes. To ensure the analysis of results only included one response from each participant, both surveys were excluded. This allowed nine surveys to be included in the results producing a participation rate of $47 \%$. A total of six teachers, or $32 \%$ of participants, participated in both the pre- and post-surveys. 
Cronbach's $\alpha$ was used to analyze the internal consistency of two items: Placement of recess positively affects academics and Placement of recess negatively affects academics. It was found that these two items were highly correlated so the negative item was removed from analyses. All other items were analyzed using the statistical package SPSS version 23.0 for Windows.

Pre-schedule change perceptions (RAL). Participants $(n=13)$ were asked how supportive they were in scheduling lunch before and lunch after recess based on a 5-point Likert scale from 5, very supportive, to 1, not very supportive. Support for RAL had a mean score of $3.46(\mathrm{sd}=1.57)$. Very supportive had the highest frequency of $5(38.5 \%)$ for this issue. Support for RBL had a mean score of $4.08(\mathrm{sd}=1.12)$. Again, very supportive had the highest frequency of $7(53.8 \%)$

Participants were asked to share how adequate they thought various feeding implications were met with RAL, on a 5-point Likert scale with 5 being completely adequate and 1 being completely inadequate. All six items evaluated scored between 2.5-3.0. See Table 1 for complete results. The item pertaining to meeting children's dietary/nutritional needs had the highest mean of $3.0(\mathrm{sd}=1.00, \mathrm{n}=13)$ while the impact on meal digestion and the impact of making sure children have enough time to eat had the lowest means of $2.54(\mathrm{sd}=1.05 ; \mathrm{sd}=1.13$ respectively, $\mathrm{n}=13)$.

Four items related to the logistics of having RAL were rated on a 5-point scale by 13 participants. A score of 5 represented very well defined while a score of 1 represented not very well defined. The highest scored item was management of sack/cold lunches with a mean score of $3.62(\mathrm{sd}=1.61)$. However, the most frequent response was very well defined, with a frequency of 5 , representing $38.5 \%$ of all responses. Behavior trends of the students were rated from 5 , very 
good, to 1, very poor, by twelve participants. Behavior in cafeteria was rated the lowest with a mean score of 2.33 with the most common score of poor being perceived by eight of the twelve respondents or $66.7 \%$. Behavior in the classroom scored marginally higher with a mean of 2.92 $(\mathrm{sd}=1.08)$. No respondent reported behavior as very good but five teachers $(41.7 \%)$ scored classroom behavior as very poor or poor.

Five items pertaining to perceptions of how RAL affects various classroom and academic performance was measured on a 5-point Likert scale from 5, strongly agree to 1, strongly disagree, by twelve participants. When asked if recess placement after lunch positively affected student academic performance the mean score was $2.50(\mathrm{sd}=.67)$. No participant reported a score of agree or strongly agree. The most frequent answer was neither agree nor disagree with seven respondents picking this answer (53.8\%). When asked if having RAL helped students focus when returning to the classroom only one participant strongly agreed. A total of $91.7 \%$ of respondents scored this measure between strongly disagree, disagree, and neither agree nor disagree producing a mean score of $2.33(\mathrm{sd}=1.15)$. See Table 1 for more results.

Post-schedule change perceptions (RBL). During the post-survey participants ( $\mathrm{n}=9$ ) were again asked how supportive they were in scheduling lunch before and lunch after recess based on a 5-point Likert scale of 5, very supportive, to 1, not very supportive. Support for RAL had a mean score of $3.22(\mathrm{sd}=1.86)$. Very supportive had the highest frequency of $4(44.4 \%)$ for this issue. Support for RBL had a mean score of $3.44(\mathrm{sd}=1.33)$. The choice neither supportive nor not supportive had the highest frequency of $5(55.6 \%)$.

Participants ( $\mathrm{n}=9$ ) were again asked to share how adequate they thought various feeding implications were but this time in regards to RBL, on the same 5-point Likert scale with 5 being completely adequate and 1 being completely inadequate. All six items were scored between 
2.78-3.56. The feeding implication related to impact on meal digestion had the highest mean of $3.56(\mathrm{sd}=1.59)$ while the feeding implication on making sure children have enough time to eat had the lowest mean of $2.78(\mathrm{sd}=1.30)$.

Four items related to the logistics of having RBL were rated by nine participants on a 5point scale with 5 representing very well defined and 1 representing not very well defined. The highest scored item was management of sack/cold lunches with a mean score of $3.56(\mathrm{sd}=1.51)$. The lowest scored item was managing hand washing which had a mean of $3.00(\mathrm{sd}=1.41)$.

Behavior trends of the students were reevaluated and scored from 5, very good, to 1 , very poor, by nine participants. Behavior in cafeteria was rated the lowest out of other behavior topics concerning RBL with a mean score of $2.56(\mathrm{sd}=1.13)$. Behavior in the classroom scored higher than in the pre-survey with a mean score of $4.33(\mathrm{sd}=.71)$. Eight participants $(89.9 \%)$ scored classroom behavior as good or very good while only one participant said behavior was neither good nor poor. No participants scored the classroom behavior as poor.

Five items pertaining to perceptions of how RBL affected classroom or academic performance was measured on a 5-point scale from 5, strongly agree to 1, strongly disagree, by nine participants. When asked if recess placement before lunch positively affected student academic performance the mean score was $3.67(\mathrm{sd}=.87)$. No participant reported a score of strongly agree or disagree. The most frequent answer was neither agree nor disagree with five respondents picking this answer (55.6\%). When asked if having RBL helped students focus when returning to the classroom only one participant strongly disagreed. Of the respondents, 89.9\% scored this measure between neither agree nor disagree, agree, strongly agree producing a mean score of $3.33(\mathrm{sd}=1.22)$. See Table 1 for results of both RAL and RBL surveys. 
Table 1

Mean Scores of Recess After Lunch and Recess Before Lunch Surveys

$\begin{array}{ll}\text { Recess After } & \text { Recess Before } \\ \text { Lunch } & \underline{\text { Lunch }}\end{array}$

Support:

1-Not very supportive; 2-Not supportive; 3-Neither supportive nor not supportive; 4-Supportive; 5-Very supportive

Scheduling lunch period before recess

$3.46( \pm 1.51)$

$3.22( \pm 1.86)$

Scheduling lunch period after recess

$4.08( \pm 1.12)$

$3.44( \pm 1.33)$

Current schedule adequately meets following feeding implications:

1-Completely inadequate; 2 -Inadequate; 3-Neither; 4-Adequate; 5-Completely adequate

Children's food consumption at lunch

$2.92( \pm 0.86)$

$3.22( \pm 1.20)$

Making sure children get enough to eat/are not hungry

$2.83( \pm 0.94)$

$3.11( \pm 1.36)$

Impact on meal digestion

$2.54( \pm 1.05)$

$3.56( \pm 1.59)$

Meeting children's dietary/nutritional needs

$3.00( \pm 1.00)$

$3.22( \pm 1.30)$

Making sure children have enough time to eat

$2.54( \pm 1.13)$

$2.78( \pm 1.30)$

Consideration of impact on special needs students

$2.77( \pm 0.83)$

$2.89( \pm 1.17)$

Current schedule defines following logistics:

1-Not very well defined; 2-Not defined; 3-Neither; 4-Defined; 5-Very well defined

Managing hand washing

$3.23( \pm 1.48)$

$3.00( \pm 1.41)$

Managing winter/rain clothes

$3.15( \pm 1.46)$

$3.44( \pm 1.24)$

Managing sack/cold lunches

$3.62( \pm 1.61)$

$3.56( \pm 1.51)$

Consideration for storing children's personal belongings

$3.15( \pm 1.21)$

$3.11( \pm 1.17)$

\section{Current behavior trends:}

1-Very poor; 2-Poor; 3-Neither good nor poor; 4-Good; 5-Very good

Children's behavior in the classroom under current schedule

$2.92( \pm 1.08)$

$4.33( \pm 0.71)$

Children's behavior in the cafeteria under current schedule

$2.33( \pm 0.89)$

$2.56( \pm 1.13)$

Current schedule affects the following measures:

1-Strongly disagree; 2-Disagree; 3-Neither agree nor disagree; 4-Agree; 5-Strongly Agree

Placement positively affect students' academic work

$2.50( \pm 0.67)$

$3.67( \pm 0.87)$

Placement helps children stay focused in the morning

$2.75( \pm 0.75)$

$2.67( \pm 1.00)$

Placement helps children stay focused in the afternoon

Placement helps children focus when returning to class after

lunch/recess

$2.42( \pm 1.17)$

$3.11( \pm 1.05)$

$2.33( \pm 1.16)$

$3.33( \pm 1.22)$

Pre- and post-survey results. There were six participants who completed both the pre- and post- schedule change survey producing paired scores for each individual. These surveys were statistically analyzed using dependent paired $t$-tests. Out of the 18 pairs of items analyzed, only one pair was found statistically significant at the $\mathrm{p} \leq .05$ level. The average score for children's behavior in the classroom increased from $3.17(\mathrm{sd}=.98)$ on the pre- survey to $4.50(\mathrm{sd}=.55)$ on 
the post-survey. The difference between the two means was statistically significant at the $\mathrm{p} \leq .05$ level $(\mathrm{t}=-2.70, \mathrm{df}=5)$.

\section{Qualitative Findings}

Findings from one-on-one interviews and open-ended survey questions allowed researchers to gain insight into the thoughts of school professionals regarding placement of recess. It was discovered during an interview with the principal that the initial idea to change the schedule to RBL came from a kindergarten teacher who presented research articles demonstrating positive outcomes for students. The principal along with teachers and eventually LRS discussed this and decided to change the schedule after winter break. When the first set of interviews took place, students had forty minutes for both lunch and recess. According to the principal, most students finished eating within fifteen minutes but had the option to use the whole forty minutes to eat if needed. When the schedule changed to RBL students had recess for twenty minutes, five minutes to get inside, and twenty minutes to eat with no additional flexibility in the schedule for slow eaters.

Recess after lunch interviews. A total of five LRS and one principal agreed to participate in individual interviews in fall 2016 when recess was after lunch. During these interview sessions, researchers allowed participants several opportunities to share their thoughts about both RAL and RBL. Researchers began by asking participants the meaning of word "recess." The common theme that emerged from each participant was "play." Participants mentioned that recess is an unstructured activity where students can simply play.

Thoughts about RAL. "Hyper" was the common theme that emerged when asked to describe the behavior trends that occurred during lunchtime (RAL). Getting the students to calm down, listen, and do what was asked was reported as being difficult. The principal stated, 
"students go from a highly structured environment to semi structured lunch time, then to unstructured recess." The principal went on to say, "When recess is over, they line up. Then we expect them to automatically switch off problems at recess and come into the classroom." The principal hoped the new schedule would help alleviate behavior issues that arose from hyperactive students by slowly winding students down during lunch prior to heading back to the classroom. The LRS comments were similar to those of the principal. One LRS stated, "Currently, we are setting them up for failure. We tell them to be quiet. Wait. Wait some more. [It would] even be hard to ask an adult to do this."

Thoughts about $R B L$. When asked various questions about what participants thought about the change to RBL almost all answers were positive in nature. Every participant was overall supportive of the change, and many thought it would lead to better nutrition and behavior. Overall, the common theme among answers were open and optimistic about RBL. One participant's positive response was, "Hopefully, they can concentrate on lunchtime. Might calm them down a bit instead of [going from] recess to class."

The professionals were asked if they anticipated any issues affecting their particular role once recess was placed before lunch. All of the participants concluded they would not be directly affected by the change. This theme was captured and summed up in one LRS comment of, "Same thing, different order. Schedule change will not affect us."

Barriers. When asked about the greatest barrier of having RAL, the LRS primarily commented on students being unfocused on eating during lunch and instead focused on playing, so the students ate less to get to recess quicker. This theme is illustrated in the statement given by a LRS, "Biggest barrier is trying to calm down, and students are not focusing on food. They scarf and hurry up to get out [to recess]." 
Participants were also asked to share what they perceived the greatest barrier would be when RBL was implemented. Several LRS thought no barriers would exist, others thought adapting to change would be the biggest barrier. For example, replies were, "Kids are use[d] to a schedule" and "Challenge is schedule change and getting into a routine." While adapting to change was the common theme among LRS, the principal had two different concerns, primarily the logistical planning before the change. First, the principal mentioned that the work schedules for many employees, such as kitchen and cafeteria staff, as well as the custodians would change slightly. Almost every other professional in the school would have a schedule shift of 5-10 minutes. This shift could have an impact on teachers who travel to various schools during the day, which could ultimately affect other schools in the process. The other concern the principal expressed was for slow eaters. With RAL students who are not finished eating could simply move to another table to finish eating then go play when finished. With RBL, on the other hand, the children would play first and only have twenty minutes to eat, so if they stayed to finish they would lose instruction time in the classroom.

Other Thoughts. Researchers ended each interview by asking participants to share any additional thoughts they had about recess scheduling. The final comments demonstrated that the participants were prepared for the recess change. The principal was open to the idea and was supportive of the change as long as it was beneficial for the students. The principal realized that issues would likely present themselves no matter how much planning happened beforehand. The LRS also thought changing the recess schedule was a good idea and were mainly concerned with getting the students into a routine once the change took place. See Table 2 summarizing major themes that emerged during interviews for select questions. 
Recess before lunch interviews. Again, a total of five LRS and one principal participated in individual interviews during spring 2017 when recess was placed before lunch. Four of the LRS participated in both pre- and post- schedule changes. One LRS that participated in fall 2016 was no longer at the school during spring 2017 and a new LRS participated. These interviews were conducted in the same manner as the first round. Many questions were the same, just slightly reworded to account for the new schedule, and new questions comparing before and after took the place of questions that were no longer relevant.

\begin{tabular}{|c|c|c|}
\hline \multicolumn{3}{|c|}{$\begin{array}{l}\text { Table } 2 \\
\text { Comparing Select Interview Themes from Recess After Lunch and Recess Before Lunch } \\
\text { Interviews }\end{array}$} \\
\hline & Fall Interview (RAL) & Spring Interview (RBL) \\
\hline \multirow{4}{*}{ How do you feel about recess before lunch? } & Optimistic about results & Beneficial results \\
\hline & Open to idea & Accept idea \\
\hline & Positive overall & Positive overall \\
\hline & Better outcomes possible & Challenge: Logistics \\
\hline \multirow{4}{*}{ What is the greatest barrier to having recess after lunch? } & Calming children & Behavior \\
\hline & Focusing children & Flow \\
\hline & Children not eating & Time \\
\hline & $\begin{array}{l}\text { Logistics } \\
\text { Overall negative } \\
\text { responses }\end{array}$ & Logistics \\
\hline \multirow{3}{*}{$\begin{array}{l}\text { What is the greatest barrier to having recess before } \\
\text { lunch? }\end{array}$} & Forming routine & Behavior \\
\hline & Change & Logistics \\
\hline & None expected & More positive responses \\
\hline \multirow{3}{*}{$\begin{array}{l}\text { Are there specific issues that affect you in your role } \\
\text { regarding recess before lunch? }\end{array}$} & No & Training \\
\hline & & More responsibility \\
\hline & & Logistics \\
\hline \multirow{3}{*}{$\begin{array}{l}\text { Please describe the current behavior trends that occur } \\
\text { during lunch time. }\end{array}$} & Hyper & No change at recess \\
\hline & Unfocused & Improved in classroom \\
\hline & Challenging & \\
\hline
\end{tabular}


Thoughts about RBL. Overall positive feelings were shared about RBL. LRS reported that students were eating more and that behavior in the cafeteria was better with the new schedule. Younger students seemed to be especially impacted by the schedule change and were showing the most improvement according to LRS. The overall theme was that RBL was a beneficial change for the students. The principal summed up the benefits by saying "Kids are eating a little bit better. Fewer recess issues coming back into school." LRS reported that children were throwing away less food because they are hungry when they come inside from playing, and all agreed that the new schedule was a positive change for the students. Throughout the entire interviews, LRS continually mentioned that food consumption was better overall.

Two themes emerged when asked about behavior. One, that behavior at recess was still the same though seemed somewhat improved inside the cafeteria; and two, that behavior when the children return to class had improved significantly. The principal said that there used to be a lot of children sent to the office after lunch for minor issues. Since the schedule change to RBL, very few students are sent to the office for minor behavior issues. The principal believed that children forget why they were upset with another student from recess when they sit down to eat lunch, so not as many social problem return to the classroom. The principal said "Lunch is interceding."

When asked which recess timing each professional preferred, every LRS said they like RBL more mainly because students were eating better than they were with RAL. One LRS comment summed up all the others, "RBL. Come in, everyone sitting, less talking, more eating." The overarching theme that developed was that RBL was viewed positively and was a beneficial change for students. 
Barriers. Despite the principal and LRS all agreeing that they liked the new schedule of $\mathrm{RBL}$, another theme emerged in the responses, which was that logistics was a major barrier to RBL. Several LRS commented that students transitioning and moving from outside recess to the lunchroom cafeteria was a challenge. When asked about feelings towards RBL, one LRS said, "Good. Do not think building was designed for flow of this, but it's good for the kids." Timing and logistics were reported as needing improvement. LRS that went outside to recess with students reported that behavior outside was the same as it was before. Several participants mentioned that children still need more time to eat and setting up for recess was time consuming and sometimes did not get done. Other participants mentioned that lining students up and getting them through the line took too much of the students' eating time, so they were rushed when they finally got to a table with their lunch tray. This participant said, "I wish kids had more time to eat. They still get rushed either way." Although all of these barriers were brought up by LRS, when asked which ones specifically impacted their job, logistics of student organization was the only one mentioned. The principal reported he was working to train staff and hire more LRS to make the movement of children and timing smoother. The principal also reported that properly trained staff would help make the transition and movement of children go faster and more efficiently.

Researchers asked participants to reflect on the barriers that were present during the RAL schedule to be able to compare barriers from RAL to RBL. Several barriers emerged including more behavior issues for teachers in the classroom, behavior issues inside the cafeteria and on the playground for LRS, the logistics of getting the students organized, and proper training. Although only asked for barriers to RAL, many participants went on to say how the RBL has helped alleviate one challenge or another. For example, one participant answered, "Greatest 
barrier was lining them up. Then they wanted to play and would not act right, now they are more calmer...they run to line up to go in and eat lunch.” The barriers to RBL seemed to be similar to the barriers of RAL, but RBL was reported as being able to provide solutions. See Table 2 summarizing major themes that emerged during RAL and RBL interviews for select questions.

Qualitative teacher questions. A total of eight teachers answered three open-ended questions asking about their perceptions of each recess timing in the fall when the schedule was RAL. Questions were able to be skipped and as a result not every teacher answered every question. A maximum of eleven teachers answered the same three opened ended questions in the spring after the schedule changed to RBL. Again, not every teacher answered every question.

Teachers were asked "What is/was the greatest barrier faced when recess is/was after lunch?" and "What will be/is the greatest barrier faced when recess is before lunch?". When the schedule was RAL teachers said that social issues among the kids was a large barrier to RAL. Teachers were also concerned with students eating too fast to have more recess time. One participant demonstrated both concerns, "Many of the social issues that take place at recess, often interfere with class... Additionally, students rush through their meals so they have more time to play at recess."

When the schedule changed to RBL and teachers reflected back to how it was before, the same two themes of social issues among students and concerns about student eating emerged as the most prevalent concerns. The same teacher has had less social issues coming back into the classroom with RBL, “After lunch I was solving social problems for 15-30 minutes. I rarely have to do this anymore. The commons themes that emerged when teachers looked ahead and anticipated barriers with RBL were time, logistics, and change. One participant listed several examples, "Hand washing, coats, students that need extra time may miss classroom instruction." 
Researchers attempted to wait an adequate amount of time before resurveying the teachers to allow adjustment to change. When resurveyed after the schedule changed to RBL, the two major themes among answers were again time and logistics. Several participants had concerns about both issues, "There are no clear procedures for anything. Where do we put cold lunches? Where [do] kids who traditionally sat at the detention table go? There is not enough time for the students to eat..."

When given the opportunity to share any additional thoughts teachers were overall optimistic about the upcoming change to RBL. One teacher commented, "I am hopeful [RBL] will allow students to get their energy out, eat more lunch, and calm down before returning to the classroom." After the schedule changed to RBL most teachers still had overall positive attitudes towards RBL but also mentioned logistical and timing problems. No participant indicated a strong desire to go back to RAL and instead some offered solutions to the problems associated with RBL.

\section{Discussion}

An increasing amount of research supports the practice of placing RBL due to the many positive benefits that result from this timing (Bounds, et al., 2009; Fenton, et al., 2015;

Hunsberger, et al., 2014; Price \& Just, 2015, Strohbehn, et al., 2016). These benefits include less food waste due to children consuming more food (Strohbehn et al., 2016), children making more nutritious food choices like choosing more fruits and vegetables (Price \& Just, 2015), and better perceived classroom behavior from teachers (Hunsberger et al., 2014).

The current study evaluated the perceptions of teachers, lunchroom supervisors, and a principal regarding perceived benefits and barriers that should be taken into consideration by other schools and administrative teams planning to make a schedule change to RBL. The results 
obtained from the surveys distributed to the teachers produced some mixed perceptions about the RBL schedule. Many teachers were very supportive of RBL during the pre-survey, however, this changed slightly when the RBL schedule was actually put into place. More teachers were very supportive of RAL after the recess timing was changed to RBL compared to when recess was actually after lunch. Cullen et al. (2015) and Fenton et al. (2015) also found mixed results during studies focusing on RBL. While the support for RBL may have declined, many of the various factors affecting students directly actually improved slightly after the RBL schedule was implemented.

Behavior in the classroom after lunch and recess was perceived to be significantly better with the RBL schedule. Behavior was a primary reason this particular school considered changing schedules, so this result supports this school's decision to continue RBL next year. Not one teacher reported the behavior as good in the classroom with a RAL schedule. However, when the schedule changed to RBL, almost $90 \%$ of teachers thought that classroom behavior improved and was either good or very good. More impressive is the fact that no participant called behavior poor with the RBL schedule. This finding supports our original hypothesis that teachers would rate classroom behavior lower when recess was after lunch.

Behavior in the cafeteria was also perceived by teachers to be marginally better with a RBL schedule. This finding corresponds to findings from Hunsberger et al. (2014) who also found that student behavior was perceived by school professionals as being better during participation in a RBL format. LRS in the current study thought that children were hyper and unfocused during lunch time, which made it challenging to get the students to stop chatting with friends and pay attention to their food during the RAL schedule. When the schedule changed to RBL, LRS reported no change in the chaotic behavior on the playground, but some believed 
behavior in the cafeteria was marginally better because children calmed down and ate more. The principal also reported less classroom behavior issues being reported to him after lunch with the RBL schedule.

Academic performance is a huge factor affecting many policies and procedures within individual schools. Poor academic performance leads to revisions in these policies. Due to the importance of this issue, perception on how the recess schedule affects academic performance was of great interest to researchers. Ideally, placement of recess, whether it be before or after lunch, should have a positive effect on academic performance or at the very least, not have a negative impact. Almost half of the teachers at the school under study disagreed to some extent that a RAL schedule positively affected student performance and no participant reported that RAL positively affected academic performance. A result like this should be a red flag indicating a more efficient schedule should be considered to help the students reach their maximum academic potential. After the schedule changed to RBL more positive perceptions were reported. Not one teacher disagreed that RBL positively affected academic performance. In fact, almost half the participants agreed that the RBL schedule had a positive impact. This is an indication that RBL does benefit the students in some way and may impact the overall performance of the entire school as well as individual students. While this is only a slight change in perceptions, it should be noted that it was positive change. This positive change should be taken into account by school administers and policy makers. Teachers are an indispensable resource when it comes to evaluating student performance, especially at such a young age when standardized testing is minimal at the elementary school level. Teacher's perceptions are sometimes the only measure decision makers have to whether a new policy is beneficial or hindering students, and this measure should not be ignored. 
Academic performance can be affected by many different factors. One of these factors is how well students stay focused on the topic being covered in class. Once again teachers had a slight but positive change in perception on recess placement affecting student classroom focus after the schedule changed to RBL. When RAL was in effect, only one teacher thought that placement helped whereas, after the schedule changed to RBL, only one participant disagreed that placement helped students focus. While this was not a statistically significant result, when paired with qualitative findings, this topic trended towards significance. This partially supports our second hypothesis that teachers would rate students' ability to focus higher with RBL. This is another strong indication that decision makers should factor into any policy changes beforehand. The participants in this study ranked most items higher, if only marginally, after the change to RBL indicating that a RBL schedule was perceived as a beneficial change for students overall. Not all issues had more positive perceptions after the RBL schedule changed. Many of the issues perceived to be worse due to the schedule change to RBL pertained to logistics. Hand washing procedures were perceived to be less defined after the schedule change to RBL. Although the logistics of storing children's belongings was an issue that scored the lowest with RAL, teachers thought that the logistics became even worse after RBL. This implies teachers perceived the RAL schedule as being inadequate for consideration for storing children's belongings but perceived the RBL schedule as being more inadequate for this issue. The same negative perception after the schedule change happened again when asked about managing sack lunches. Teachers thought this procedure was not as clear after the change to RBL. The only other issue that had more negative perceptions after the change to RBL, besides teacher preference, was the issue that RBL did not help student stay focused in the morning as well as 
the RAL schedule. All other issues were perceived to be more positive with the RBL schedule and thus more beneficial to students.

Almost all of the negative perceptions towards RBL related to logistical obstacles while benefits to students were perceived as positive with the new schedule. These mixed perceptions may be due to inadequate logistical planning and preparation. Bounds et al. (2009) found that logistical issues prevented schools from implementing RBL. Hunsberger et al. (2014) also found that scheduling issues and logistical problems prevented RBL schedules from being implemented in elementary schools. The current study also found similar results. Issues that pertained to logistical planning typically scored lower after RBL was implemented. However, issues regarding the academics and behavior of children typically scored higher after RBL was implemented. These results suggest that RBL does produce perceived positive benefits from school professionals but detailed planning, preparation, and logistical barriers should be anticipated and resolved before implementation of RBL.

During interviews with LRS and the principal, logistical issues were rarely mentioned during RAL answers. However, when interviewed again about RBL, logistical issues and challenges were mentioned by at least one participant in every single question/answer, even those not pertaining to logistics. Again, this demonstrates how crucial it is for policy makers to plan ahead, anticipate, and solve as many logistical issues as possible before implementing a RBL policy. Policy makers should also ask for feedback from school professionals and reevaluate plans after a RBL policy is effective. For example, after this school started a RBL policy, the flow of children from outside to inside while moving other students proved to be a challenge. Instead of ignoring this obstacle, LRS formed a solution to the problem and informed 
the principal. The flow was improved greatly by simply using two different sets of doors, but without this open communication this challenge might have been left unresolved.

Despite issues with logistics, LRS and the principal all had almost exclusively positive remarks to RBL. When asked what participants expected from RBL when recess was still occurring after lunch, participants were open to the idea and optimistic about the change. After the schedule change participants had fully accepted the idea and confirmed they witnessed beneficial results daily. This attitude is despite the fact that the new schedule of RBL was reported to have directly impacted their roles. During the RAL schedule, participants believed that the schedule change to RBL would have no impact on their role. When re-interviewed after the schedule change took place though, participants answered that their role of LRS was impacted in some way because of RBL. Most LRS agreed that they now had more responsibility and the pressure was on them to control the flow of children. If they did not move them from one place to the next in an efficient and timely fashion they would miss out on valuable playing or eating time. Others mentioned how they had less time to prepare before the students came and sometimes did not have enough time to set up all the recess equipment. The principal's role was also directly affected by the new schedule in regards to figuring out logistics and training LRS properly so they had all the tools necessary to handle the additional responsibilities on the playground.

Even with additional responsibilities and pressures, every interviewed participant answered that they preferred RBL over RAL. Most went on to say they preferred RBL because the children were eating more food at lunch. The participants were still supportive of RBL despite challenges they had not anticipated. This overwhelming support for RBL by these school professionals should clearly indicate to policy makers that this is a policy worth investigating to 
determine if beneficial results could result from a policy change like it did for this school under study.

Though the teachers had months between the first time they participated in answering the survey and the second, similar responses to all questions were given both times. It is interesting that the issues that teachers anticipated would be barriers with RBL are exactly the same obstacles experienced after the schedule was changed. One would expect that anticipated barriers would have been addressed beforehand to make the transition smoother and more effective. This demonstrates how vital it is to get feedback from school professionals who have worked with children long enough to know ahead of time what the issues will likely be. It is unfortunate that these professionals did not have a stronger voice before the schedule was changed because some of the issues experienced may have been prevented or at least addressed with appropriate knowledge and planning. However, it is a positive and telling result that teachers looking back on RAL were not upset or desired to go back to a RAL schedule. Even before the schedule changed, participants were open and optimistic about RBL and hoped for positive outcomes. While many teachers stated some problems that need addressed with the RBL schedule, many said they liked the new schedule better and had overall positive comments. There were minimal reports of social issues in the classroom after the schedule changed to RBL. Comments focused on obstacles with the change, implying that if the obstacles were resolved, a working system that benefited both students and professionals could be established. These identified problems should be taken into account and solutions formulated to support the positive benefits identified by teachers. 


\section{Conclusion and Application}

This study served to explore and evaluate the perceptions of teachers, principals, and lunchroom supervisors about recess placement both before a schedule change and after the change took effect. The key finding from this study was that logistical planning needs to be a priority of policy makers. School professionals should be clearly informed about the changes being made, how any changes may affect their job directly or indirectly, and provided adequate training to allow every school professional the best opportunity to contribute to a successful schedule change. Professionals should have a clear plan of action before implementing a RBL schedule. Challenges and achievements expressed by professionals who have already undergone the change are invaluable for this plan of action.

Findings from this research support the idea that students benefit from a RBL schedule by being perceived by professionals to eat better at lunch and behave marginally better as well. This contributes to a growing body of research supporting placing recess, which traditionally occurs after lunch, to before lunch because of increased nutrient intake, better behavior, and improved learning (Bounds, et al., 2009; Fenton, et al., 2015; Hunsberger, et al., 2014; Price \& Just, 2015; Strohbehn, et al, 2016).

Though there is substantial evidence supporting many benefits of a RBL schedule, limited research has been conducted evaluating the perceptions of school professionals who are the adults that directly see any positive benefits or challenges a schedule change produces. Before deciding to make a schedule change to RBL, a perspective from school professionals should be considered. A study by Bounds et al., (2009) focused on perceptions of barriers in regards to implementing a program but did not evaluate perceptions after a policy change was actually implemented. Several gaps in the literature regarding faculty and staff perceptions on 
RBL exist. More research is needed to determine the perceptions of faculty and staff about RAL versus RBL and their perceptions on the impact recess placement has on students when a policy change is actually implemented.

Findings indicate that a well thought out plan of implementation and change are needed before jumping into a RBL schedule. Almost every participant commented about the logistics of recess scheduling at some point during this study. While school professionals do typically take time to plan and anticipate challenges, paying attention to research indicating known obstacles may not always be considered. The current study clearly outlines major logistical errors that were either not planned for or not adequately addressed at the time of implementation. Using this data will help future schools know what to expect beforehand to have a better approach to the situation overall.

This study also benefits school nutrition professionals. Limited studies have been conducted evaluating perceptions of other school professionals regarding the placement of recess. Most of the professionals in this study commented on how much more food the students ate after the schedule changed to RBL. Though this is not a proven quantitative number, the number of positive comments about food intake cannot and should not be ignored. RBL contributes to students eating better at school and the current study, along with many others, supports that point (Bounds, et al., 2009; Fenton et al., 2015; et al., 2014; Price \& Just, 2015, Strohbehn, et al., 2016).

A deeper understanding of why participants have certain opinions is needed for a complete evaluation of how and why policy changes affects them and thus their perceptions of how the new policy affects their students. Interviews with teachers may help bridge this gap. Future studies should continue to assess the perceptions of school professionals before and after 
a schedule change, and a study with larger schools would allow for more participants and follow up the next year to evaluate if initial challenges have been resolved.

Though not all results were significant, a better understanding of school professionals' perceptions about the placement of recess was gathered from this study. This research benefits this particular school district and other local districts considering a recess placement policy change. Not all schools in this area support changing the placement of recess. The results of this study may be useful for school administrators and other school staff including principals, teachers, and lunchroom supervisors considering changing schedules from a RAL to RBL format.

Though not mentioned by participants, cost is another factor that may determine if implementing a RBL policy is appropriate or even possible. After the school in this study implemented a RBL policy, teachers and staff had to stay 5-10 minutes later than they did with RAL. Some employees, like kitchen staff and janitors added even more time. Though the time added is minimal, this represents an increase in hourly wages and salary. This small increase can add up quickly when it affects every employee in the school. Policy makers should keep this in mind when weighing RAL to RBL. However, the many proven benefits to students regarding nutrition, behavior, and academic performance should outweigh this potential limited additional cost.

This study is not without limitations. First, this study was conducted at one suburban elementary school in the Midwest so cannot be generalized to larger schools in urban areas or schools in other parts of the country. Second, since this study was conducted at one small school, the sample size of school professionals is relatively low. However, participation and response rate was high with $32 \%$ of teachers participating in both pre and post surveys. Also, interviews 
with participants were not recorded and transcribed verbatim. However, two different researchers took notes during interviews and compared notes for consistency. Despite these limitations, results from this study support and fall in line with similar studies suggesting valid and useful results for all policy makers considering a RBL schedule change to benefit students (Bounds et al., 2009; Fenton et al., 2015; Hunsberger et al., 2014; Price \& Just, 2015, Strohbehn et al., 2016). 


\section{CHAPTER II: EXTENDED LITERATURE REVIEW \\ National School Lunch Program}

Since its inception in 1946, the National School Lunch Program (NSLP) and the United States Department of Agriculture: Food and Nutrition Service (USDA:FNS) have provided billions of lunches to poverty stricken students (USDA, 2017a). The NSLP is a federal government meal program that provides both free and reduced-priced lunches to students at participating schools (FNS, 2016). Schools must serve 'nutritionally balanced' meals by meeting standards set by the USDA: FNS (FNS, 2016). In a School Health Policies and Practices Study (SHPPS) conducted in 2014 by the Centers for Disease Control and Prevention (CDC) (2015) researchers discovered that roughly $85 \%$ of schools in America participate in the NSLP. This large participation rate allowed almost 30.5 million students to receive a free or reduced lunch in the 2015 fiscal year nation wide which translates into over 5 billion student lunches served (USDA, 2017b). In Illinois alone, almost 185 million lunches were served to the 1.1 million students who participated in the NSLP in fiscal year 2015 (USDA, 2017b). The school district in which the current research took place had 3,998 students participate in the NSLP during the 2015-2016 school year. The specific school where the study was conducted had an average enrollment of 424 students, but a lunch participation rate of only $86 \%$ since not every student ate lunch every day translating into a daily participation rate of roughly 365 students for the 20152016 school year. Both public and nonprofit private schools may participate and receive a financial subsidy and food items from the USDA for every meal served if they comply with federal guidelines (USDA, 2017a).

Beginning in 2012, any school receiving monetary assistance from the NSLP must follow these guidelines for every lunch service: provide $1 / 2-1$ cup of fruit, provide $3 / 4-1$ cup of vegetables, 
serve only whole-grain products, limit saturated fat to less than $10 \%$ of calories, and limit trans fat to zero grams per serving (Marcason, 2012). In addition, schools must also meet minimum ranges for calories, grains, meat/meat alternatives, dark green, red/orange, beans/peas (legumes), starchy, and other vegetables. These new regulations to the NSLP are a result of the Healthy, Hunger-Free Kids Act of 2010 which regulated funding and established policies not only for the NSLP but for many other child and elderly food programs (USDA, 2017c). The Healthy, Hunger-Free Kids Act of 2010 also allowed the USDA to make substantial changes to the guidelines for the first time in 30 years, which improved nutritional requirements and fight against hunger for millions of students across the United States. The act not only established higher nutritional guidelines for students qualifying for free and reduced price lunches, it made application to the program easier, allowing 115,000 additional students to participate, and it also increased the reimbursement rate for schools providing NSLP meals that meet the set guidelines (USDA, 2010). These guidelines also correspond to the USDA 2015-2020 Dietary Guidelines for Americans, which are supported by scientific evidence and put in place to help Americans follow a healthy diet and prevent chronic diet-related diseases to improve overall health (USDA, 2015). One diet-related epidemic affecting children that can be prevented is obesity (Daniels, 2006; Halpern et al., 2010).

\section{Childhood Obesity Costs}

There are more than 12.7 million obese children and adolescents in the United States, according to the CDC (2016), which accounts for $17 \%$ of the entire childhood population. In elementary school aged children ages 6-11, the same age group as children in the current study, the obesity rate correlates at $17.5 \%$. Obesity is a preventable condition and is defined by the World Health Organization (WHO) as having a body mass index (BMI), which is an index 
measure of weight-for-height, of 30 or higher (2016). Children are being affected by immediate and long-term obesity-related health conditions that previously only affected adults, which may lead to unhealthy adult lives and shorter life spans (Daniels, 2006; Halpern et al., 2010). These obesity-related health conditions include depression, hypertension, orthopedic complications, asthma, insulin resistance, sleep apnea, and metabolic syndrome (Daniels, 2006; Halpern et al., 2010). Battling this rise in childhood obesity and the chronic diseases that result, along with the economic, social, and monetary costs associated with obesity in children has been the source of much research (Bhatt, 2014; Daniels, Halpern et al., 2010; 2006; Sontag, Ali, Lehnert, Konnopka, Riedel-Heller, \& Konig, 2015). Children who remain obese throughout childhood have a greater likelihood of staying obese in adulthood, which is a health hazard as obese adults have a greater chance of developing diabetes, cardiovascular disease, and secondary complications contributing to death (Daniels, 2006).

The number of overweight and obese children continues to rise, which means this generation is at a greater risk of obesity related health consequences than their predecessors (Daniels, 2006; Halpern et al., 2010). This translates into "the possibility that the current generation of children could suffer greater illness or experience a shorter lifespan that that of their parents-the first such reversal in lifespan in modern history" (Daniels, 2006, p. 61). Research has been conducted to determine the cost of medical care for adults who remain obese after childhood (Sontag et al., 2015). This research found that adults who were overweight or obese at any point during childhood have higher lifetime costs; 3.7 times higher for men and 5 times higher for women compared to normal weight range peers. These excess costs are even higher for individuals who are considered obese than they are for individuals who are only classified as overweight. 
Other research has focused on determining the cost of medical care and the costs associated with children missing school due to obesity related problems. Bhatt (2014) conducted an analysis on two national surveys, the first including school food administrators from 41 states and 916 schools who answered questions about state school nutrition laws and the second including 1287 students, parents, principals, and food service managers in $1^{\text {st }}-12^{\text {th }}$ grade from 179 schools who answered questions about diet, nutrition, and exercise behaviors of students. Bhatt (2014) hypothesized that making student lunches just a mere ten minutes longer, resulting in a reduction of child obesity, would produce a cost savings of almost $\$ 33$ million in two years and reduce national student absences by 700,000 days.

Obesity in childhood not only results in medical consequences but psychological conditions as well (Sontag et al., 2015). For example, obese children may struggle with peer acceptance, hence forming meaningful relationships with peers is significantly impaired (Daniels, 2006). Compared to normal weight range children who make social networks and relations with other children, overweight children tend to be isolated and tend to develop peripheral relations with others (Daniels, 2006).

These high costs associated with childhood obesity show an acute need to balance energy intake and expenditure in children. Elementary schools are a crucial platform in which we are able to address these needs on a grand scale. “... The more an environment consistently promotes health behavior, the greater the likelihood that such behavior will occur" (Lobstein et al., 2015, p. 2510-2511). To reach large populations of children and combat childhood obesity, an ideal place to promote healthy behaviors is through the public education system.

School lunch is important for many students who qualify for free or reduced lunch because these children are at higher risk of being food insecure at home. Metallinos-Katsaras, 
Must, and Gorman (2012) found that children who do not go hungry but are consistently food insecure are strongly associated to be affected by childhood obesity depending on weight of the mother. Providing a nutritious meal at lunchtime can not only prevent food insecure children from going hungry but also allow every student access to a nutritious and balanced meal. Eating balanced meals is important in warding off weight gain but physical activity plays a part as well.

\section{Recess}

When recess occurs after lunch, children must choose between food and exercise, both of which are essential for a healthy life (Patt, 2011). Recess during the school day is an important outlet that allows children to expend excess energy. However, the importance of recess for children is often overlooked or ignored and many see no substantial reason to have recess in the school day, according to the International Play Association (IPA) (2014). Children are able to relax and cope with building stress from being challenged mentally in a confined classroom when they are able to engage in recess (Ramstetter, Murray, \& Garner, 2010). Recess is vital to a child's development as it provides for social, emotional, cognitive, and intellectual fulfillment needs, but most importantly for this discussion, recess also provides a means for children to expend excess energy (IPA, 2014). Social needs of children are filled through recess by giving children the opportunity to interact and learn about peers from different backgrounds and cultures. Recess provides for emotional needs by giving children the opportunity to get away from peers they are not getting along with so they can rethink the situation and by providing an outlet for children to release stress. Cognitive needs of children are filled through recess by providing children with unstructured free time that allows them to be curious, investigate, and create which feeds children's imagination. Recess fills intellectual needs by giving children a break from structure, while continuing to teach children vital life skills and then also provides 
balance, which helps students remain focused when returning to the classroom and structured lessons. Recess also offers physical activity, which is a crucial contributor to a child's growth and development. In summary, recess "provides[s] the opportunity for children to be active in the mode of their choosing, to practice movement and motor skills, and to engage in interactions with their peers" (Ramstetter, Murray, \& Garner, 2010, p. 522). The IPA (2014) states, "Among 5 to 8 year-olds, $40 \%$ have significant cardiac risk factors including obesity, high blood pressure, high cholesterol, and an inactive lifestyle." Clearly, "eliminating recess is counter productive" (IPA, 2014).

\section{Increased Lunch Time}

One idea researchers have to lower energy intake, thus combating childhood obesity, among elementary aged students is to give students more time to eat lunch. A longer lunch is important for several reasons. After analyzing several national school surveys, Bhatt (2014), concluded that the length of lunch can affect body weight of students in three separate ways: skipped lunches, poor energy-dense food choices, and overeating due to fast pace. Students may skip eating lunch altogether if time is too short which can lead to overeating and consumption of more calories later in the day when students have become over hungry. Bhatt (2014) also found that students with less time to eat lunch do in fact ingest less calories than kids with longer lunches, but they also consume more calories at dinner. These students do not have as much time to expend excess calories consumed, resulting in weight gain. When students do not have adequate time to eat, they may eat prepackaged convenience items that are energy dense and nutrient poor. For example, eating applesauce which has 194 calories instead of eating a fresh apple which only contains 81 calories. Children need to consume more nutrient-dense foods and fewer energy-dense products (Lobstein et al., 2015). Students with a short lunch may overeat 
because they are eating too quickly to know when they have become full, leading to students consuming more calories than they would have if they had been given the chance to eat slowly (Bhatt, 2014).

Areni and Black (2015) conducted a study on savoring food and satiation and found that encouraging the public to take the time to savor and enjoy food would be beneficial in reducing the amount of food and thus calories consumed. The same level of enjoyment can be achieved by eating less food and calories when a person reduces the rate of ingestion. By practicing mindful eating at meals with specific attention to the taste of the food by keeping the eyes shut, and increasing the number of bites taken, one can enjoy less amounts of food more thoroughly. Short lunches do not allow for the slow consumption and enjoyment of food, which can lead to higher calories ingested due to fast eating (Bhatt, 2014). This is because it takes up to 15-20 minutes for satiety or fullness signals to reach the brain (British Nutrition Foundation, 2013). The delay in satiety, or when a person feels full after eating a meal, is due to the fact that many bodily processes must happen before the brain senses fullness. This process includes sensory receptors becoming active in the stomach in the presence of food which signals for hormones to be released into the stomach that signals enzymes and acids to be released. All of these signals are then sent to the brain to regulate the amount of energy we ingest and eventual feeling of fullness. This delay means that a person actually becomes full 15-20 minutes before they start to physically feel fullness. Students who have a full thirty minutes to eat have the opportunity to respond to these satiety signals and stop eating before they overeat. Students who only have fifteen minutes to eat do not and many overeat without realizing it until later. When a person is appropriately satiated or full after eating a meal they are less likely to overeat at the next meal 
and/or go longer between meals due to a decreased urge to eat (British Nutrition Foundation, 2013).

In 2006, the average lunch period for Kindergarden- $12^{\text {th }}$ grade students was thirty minutes, but this does not mean students were able to eat a full thirty minutes (Bhatt, 2014). The resercher found the average reported time students spend in line waiting to be served food is 5.5 minutes, which cuts into eating time. After controlling for other factors that decreased eating time at lunch, such as tray return and paying for food, Bhatt (2014) discovered the average time students actually have time to sit and eat was only 22.7 minutes. Bhatt (2014) hypothesized from findings that a simple 10 minute increase in lunchtime would, on average, lower BMI 1.2\% and the likelihood of an overweight classification by $2.5 \%$. Though a longer lunch period would be beneficial to students to maintain a healthy weight, a longer lunch period has its own costs associated with it, including taking instructional time away from core classes or from noncore activities like art or physical education.

\section{Recess Before Lunch (RBL)}

However, there is a way to increase the length of students' lunches while only increasing the school day by a few minutes. There has been a recent movement and corresponding research supporting placing recess, which traditionally occurs after lunch, to before lunch (Bounds, Nettles, \& Johnson, 2009; Fenton, Rosen, Wakimoto, Patterson, Goldstein, \& Ritchie, 2015; Hunsberger, McGinnis, Smith, Beamer, \& O’Malley, 2014; Price \& Just, 2015, Strohbehn, Strohbehn, Lanningham-Foster, Litchfield, Scheidel, \& Delger, 2016). According to Patt (2011), this movement really started to gain ground in 2002 after four Montana elementary schools underwent a RBL schedule change and participated in a year long plate waste study and found that students ate more, drank more milk, and had better behavior in the classroom after lunch. 
Strohbehn et al., (2016) stated that placing RBL leads to “...increased nutrients intake at lunch, decreased afternoon behavioral issues, and increased afternoon learning efficiency...” (p. 1). There are several other benefits to having RBL. Students typically waste less food (Strohbehn et al., 2016), make more nutritious food choices such as eating more fruits and vegetables (Price \& Just, 2015), and have better perceived classroom behavior (Hunsberger et al., 2014). This may be because students are not rushing to be "done" with their meal to have more time to play which results in increased feelings of hunger later in the day (Price \& Just, 2015). In fact, the CDC (2015) conducted a survey and found that elementary students spend an average of 26.9 minutes playing at recess but only have an average of 24.2 minutes to eat lunch once they finally are seated at a table. This demonstrated how elementary students spend more time playing than eating in the cafeteria.

In a study conducted by Price and Just (2015), 22,939 students from seven elementary schools in the same school district were evaluated to determine if a RBL schedule change would affect the amount of fruits and vegetables students consumed. Researchers found that students who underwent a RBL schedule change had a 54\% increase in fruit and vegetable consumption and a $45 \%$ increase in the amount of children who consumed at least one serving of fruits or vegetables compared to students who continued to have recess after lunch (RAL). The authors concluded that a policy change to RBL had the potential to be "the most cost effective way that schools can use to increase the consumption of fruits and vegetables during school” (p. 29) which would also lead to a decreased cost associated with food waste.

Strohbehn et al. (2016) conducted a mixed methods study with three school districts for a total of 15,474 students who were willing to change from a RAL to RBL format during the middle of the school year. Researchers focused on collecting plate waste data from $3^{\text {rd }}$ graders 
and found that students threw away less grains, meat/meat alternatives, and fruits when recess occurred before lunch, though more vegetables by weight were discarded after the change. Researches developed a best practices guide for policy makers considering making a schedule change to RBL.

In a mixed methods study focusing on Kindergarten- $2^{\text {nd }}$ grade students plate waste while pilot testing RBL, Hunsberger et al., (2014) found that children who had RBL consumed more milk than those with RAL and were thus " 1.5 times more likely to meet the nutritional guidelines for calcium intake and total fat intake" (p. 7). Students who participated in RBL also had fewer teacher reported afternoon behavioral issues in the classroom than students who had RAL. During structured interviews with fifteen teachers, five food service workers, and six educational aids, teachers noted that students with RBL were ready to learn and less distracted when returning to the classroom. Researchers concluded that "the nutritional and social benefits observed indicate that changes to the school environment can positively impact nutritional intake" which proves that a policy change is justified (p. 10). This scientific evidence is either not reaching policy makers or has been overlooked.

Despite these positive benefits for students, the CDC found that only $11 \%$ of elementary schools nationwide have a RBL policy in effect for all elementary grades (CDC, 2015). A much higher proportion of schools have a RAL policy, with $26.2 \%$ of schools nationwide reporting recess immediately following lunch for every elementary grade and $38.2 \%$ reporting that no grade had a regularly scheduled recess before lunch. Other schools reported that some grades were allowed RBL but other grades had RAL or that recess and lunch did not occur together at all. The CDC also found that more than $90 \%$ of elementary students participated in a regularly scheduled recess period as part of the school day. This means that a RBL policy could potentially 
impact the eating behaviors of $90 \%$ of the nation's student population. A vast majority of the nation's students are not being taught good eating behaviors early in life which puts them at risk for an unhealthy adult life.

\section{Conflicting Results}

There are some research studies that have not found results supporting any benefits to RBL. However, these studies focus specifically on fruit and vegetable (F/V) intake and typically find no significant results, conflicting results, or no change in eating behaviors of students (Cullen, Chen, Dave, Johnson, 2015; Fenton et al., 2015; Hunsberger et al., 2014). Cullen et al., (2015) conducted a plate waste study involving 1,149 elementary and 427 intermediate students from twelve Houston area schools to determine how many servings of F/V students consumed. Researchers found mixed results when comparing how many servings of $\mathrm{F} / \mathrm{V}$ children took when they were allowed three portions versus two portions. Researchers also found that significantly more children with access to three F/V options took and consumed more dark green, starchy and total vegetables, however, these same students took less whole grain, juices, and protein options which are also important components of a balanced diet. These authors suggest more research is needed to determine what factors influence student food preference and consumption. While it is important to consider other factors that may influence a student's F/V consumption, it should be noted that this study only looked at how effective the new NSLP regulations were in increasing F/V consumption and did not take timing of recess into consideration.

Despite finding positive outcomes associated with RBL, such as improved teacher reported behavior and increased calcium intake, Hunsberger et al., (2014) also found that the median percent of fruits, vegetables, and main dishes eaten by students were the same whether they had RBL or RAL which led the authors to conclude that "recess order was not significantly 
associated with the probability of a student meeting the USDA nutritional standards for total calories, protein, Vitamin C, Vitamin A, or iron" (p. 7). Researchers also concluded that their findings imply that elementary aged students in $2^{\text {nd }}$ grade or lower only eat food that they like and are familiar with. This finding may impact the results of any study focusing on nutritional intake of children of this age regardless of other experimental factors and should be considered by future researchers.

In a study conducted by Fenton et al. (2015) researchers divided 2,167 students from thirty-one elementary schools and four school districts into students who had RBL and those who had RAL and compared F/V consumption. Reserchers did not find any significant differences in F/V intake in children who played before lunch with those who played after lunch. Researchers concluded that many factors could play a role and vary from school to school when comparing F/V intake and the timing of play. This study had the unique inclusion criteria for requiring participating schools to have more than $50 \%$ of students qualify for free or reduced price lunches; this implies researchers were looking for at-risk students from NSLP participating schools. However, this study was conducted before the Healthy Hunger-Free Kids Act was put into place, meaning children were offered much different portions and options at lunch compared to other studies conducted after the act was established, which may result in unreliable and outdated results. These authors urged schools to consider the lack of research for increasing F/V consumption in relation to play time before making any policy changes and called for more research on this subject. It is important to remember that many schools consider a policy change to RBL not only to increase $\mathrm{F} / \mathrm{V}$ intake but also to increase overall nutrient consumption, promote learning in the classroom, and/or improve disruptive behaviors. In other words, many factors are considered when making a policy change and not just F/V consumption. 


\section{Perceptions of School Staff}

Before deciding to make a change in schedule to RBL, a perspective from administrators and school professionals should be considered. Bounds et al., (2009) conducted a mixed methods study to "examine the perceptions of school nutrition directors, principals/assistant principals, and teachers regarding issues important to consider when scheduling recess in relation to lunch, and to describe practices related to successfully implementing a recess before lunch program" ( $\mathrm{p}$. 1). Surveys were returned by 332 food service directors, principals/assistant principals, and teachers, out of these professionals forty-seven participated in eight focus group meetings. Researchers reported "barriers commonly identified by school professionals included preservation of instructional time, logistical issues such as addressing hand washing and winter clothing, and scheduling concerns" (p. 3) which prevented schools from implementing RBL. These barriers cover a wide variety of topics that need to be addressed. However, participants rated issues regarding child well being as the most important to consider when implementing RBL. Issues relating to child well being included "maintain instructional time, children's academic performance, and children's health and well-being" (p. 12).

Strohbehn et al., (2016) conducted structured interviews to identify the perceptions of school stakeholders from three different school districts in regards to implementing a RBL policy. Most stakeholders believed that a RBL policy would increase the amounts of nutrients consumed by students at lunch but would create barriers in regards to scheduling and logistics. However, after the RBL policy was actually implemented, one school district actually reported less perceived intake of nutrients at lunch because students talked more leaving less time to eat. All three school districts reported that they were able to overcome almost all the barriers related to scheduling RBL because of good communication and planning beforehand though some 
logistical challenges remained unresolved. Finally, researchers reported that perceptions of classroom and cafeteria behavior varied by district.

Another study conducted by Rainville, Wolf, and Carr (2006) utilized focus groups with school administrators, teachers, parents, and nutritional professionals to determine the most common barriers to implementing a RBL policy. Researchers conducted pilot focus groups with school administrators, faculty, parents, and nutrition professionals including nutrition directors, kitchen mangers, and lunchroom supervisors. Researchers used these focus groups to "refin[e] and finaliz[e] a series of questions designed to explore barriers to recess placement before lunch in elementary schools". Researchers in the current study adapted questions for interviews from this same series of questions that had already been pilot tested. Administrators said the most common barriers to a RBL policy was loss of academic time, logistical complications, resistance to change. Teachers mentioned the same barriers but also thought that exercise, weather, and flexibility of administrators were also obstacles of a RBL policy. Future studies were recommended to focus on evaluating pre- and post- schedule change outcomes to determine if positive changes result for the same group of students.

Other topics researchers found that should be considered before a schedule change included personnel support, workload, student behavior, child nutrition and hunger level, and leadership, teamwork, and positive attitudes regarding the program (Bounds et al., 2009). Hunsberger et al., (2014) found two larger barriers in implementing a RBL program. First was a scheduling barrier. Kitchen and cafeteria workers had to work a small amount longer each day, which led to increased costs to the budget. Second was a barrier to proper hand washing after recess since the school that participated in the study did not have a hand washing sink in or near the cafeteria. This caused a $\$ 300$ cost in sanitizing hand wipes for the five day study and not all 
parents agreed this was an appropriate substitution to regular hand washing. Patt (2011) echoes these same problems with a RBL schedule and states that scheduling and sanitation are the most common problem areas reported by both school administrators and parents. Soap and warm water is the recommended method of hand washing to kill germs, but this is not always possible at schools that do not have sinks near the cafeteria; as a result "many schools install handsanitizing dispensers directly on lunchroom walls" (p. 69).

Even with this research, several gaps in the literature regarding faculty and staff perceptions on RBL exist. More research is needed to determine the perceptions of faculty and staff about RAL versus RBL and their perceptions on its impact on students. This study will fill a gap in literature by assessing the perceptions that teachers, principals, and lunchroom supervisors have about recess after lunch, then again after a schedule change to RBL. The results of this study may be useful for school administrators and other school staff including principals, teachers, and lunchroom supervisors considering or preparing for a schedule change from a RAL to RBL format. 


\section{REFERENCES}

Areni, C. S., \& Black, I. (2015). Consumer’s responses to small portions: Signaling increases savoring and satiation. Psychology and Marketing, 32(5), 532-543. doi:10.1002/mar.20798

Bhatt, R. (2014). Timing is everything: The impact of school lunch length on children's body weight. Southern Economic Journal, 80(3), 656-676. doi:10.4284/0038-4038-2012.102

Bounds, W., Nettles, M. F., \& Johnson, J. T. (2009). Recess before lunch programs in elementary schools: Perceptions and practices of school professionals. The Journal of Child Nutrition and Management, 33(1). Retrieved from https://schoolnutrition.org/jcnm/

British Nutrition Foundation. (2013, Nov.) Understanding satiety: Feeling full after a meal. Retrieved from https:/www.nutrition.org.uk/healthyliving/fuller/understandingsatiety-feeling-full-after-a-meal.html

Centers for Disease Control and Prevention. (2016, Dec. 6). Childhood obesity facts. Retrieved from https://www.cdc.gov/obesity/data/childhood.html

Centers for Disease Control and Prevention. (2015). Results from the school health policies and practices study 2014. Retrieved from https://www.cdc.gov/ healthyyouth/data/shpps/pdf/shpps-508-final_101315.pdf

Cullen, K. W., Chen, T., Dave, J. M., \& Jensen, H. (2015). Differential improvements in student fruit and vegetable selection and consumption in response to the new national school lunch program regulations: A pilot study. Journal of the Academy of Nutrition and Dietetics, 115(5), 743-750. doi:10.1016/j.jand.2014.10.021 
Daniels, S. R. (2006). The consequences of childhood overweight and obesity. The Future of Children, 16(1), 47-68. Retrieved from http://www.futureofchildren.org/sites/ futureofchildren/files/media/childhood_obesity_16_01_fulljournal.pdf

Fenton, K., Rosen, N. J., Wakimoto, P., Patterson, T., Goldstein, L. H., \& Ritchie, L. D. (2015). Eat lunch first or play first? Inconsistent associations with fruit and vegetable consumption in elementary school. Journal of the Academy of Nutrition and Dietetics, 115, 585-592. doi:10.1016/j.jand.2014.10.016

Halpern, A., Mancini, M. C., Magalhaes, M. E., Fisberg, M., Radominski, R., Bertolami, M. C., ... Nery, M. (2010). Metabolic syndrome, dyslipidemia, hypertension and type 2 diabetes in youth: From diagnosis to treatment. Diabetology \& Metabolic Syndrome, 2(1), 1-20. doi: 10.1186/1758-5996-2-55

Hunsberger, M., McGinnis, P., Smith, J., Beamer, B. A., \& O’Malley, J. (2014). Elementary school children's recess schedule and dietary intake at lunch: a community-based participatory research partnership pilot study. BMC Public Health, 156(14). doi:10.1186/1471-2458-14-156

International Play Association: American Association for the Child's Right to Play. (2014). The case for elementary recess. Retrieved from http://www.peacefulplaygrounds.com/ pdf/right-to-recess/the-case-for-recess.pdf

Lobstein, T., Jackson-Leach, R., Moodie, M. L., Hall, K. D., Gortmaker, S. L., Swinburn, B. A., ..., McPherson, K. (2015). Child and adolescent obesity: Part of a bigger picture. Lancet, 385, 2510-2520. http:dx.doi.org/10.1016/S0140-6736(14)61746-3 
Marcason, W. (2012). What are the new national school lunch and breakfast program nutrition standards? Journal of the Academy of Nutrition and Dietetics, 112(7), 1112. doi:10.1016/j.jand.2012.05.017

Metallinos-Katsaras, E., Must, A., \& Gorman, K. (2012). A longitudinal study of food insecurity on obesity in preschool children. Journal of the Academy of Nutrition and Dietetics, 112(12), 1949-1958. https://doi.org/10.1016/j.jand.2012.08.031

Patt, M. J. (2011). Starving for recess. District Administration, 47(5), 66-70. Retrieved from https://www.districtadministration.com/article/starving-recess

Price, J., \& Just, D. R. (2015). Lunch, recess and nutrition: Responding to time incentives in the cafeteria. Preventative Medicine, 71, 27-30. doi10.1016/j.ypmed.2014.11.016

Rainville, A. J., Wolf, K. N., \& Car, D. H. (2006). Recess placement prior to lunch in elementary schools: What are the barriers? The Journal of Child Nutrition and Management, 30(2). Retrieved from https://schoolnutrition.org/uploaded Files/ 5_News_and_Publications/4_The_Journal_of_Child_Nutrition_and_ Management/Fall_2006/8-rainville.pdf

Ramsetter, C. L., Murray, R., \& Garner, A. S., (2010). The crucial role of recess in schools. Journal of School Health, 80(1), 517-526

Sontag, D., Ali, S., Lehnert, T., Konnopka, A., Riedel-Heller, S., \& Konig, H. H. (2015). Estimating the lifetime cost of childhood obesity in Germany: Results of a Markov Model. Pediatric Obesity, 10(6), 416-422. doi:10.1111/ijpo.278 
Strohbehn, C. H., Strohbehn, G. W., Lanningham-Foster, L., Litchfield, R. A., Scheidel, C., \& Delger, P. (2016). Impacts of scheduling recess before lunch in elementary schools: A case study approach of plate waste and perceived behaviors. The Journal of Child Nutrition \& Management, 40(1). Retrieved from https://schoolnutrition.org/uploadedFiles/5_News_and_Publications/4_The_ Journal_of_Child_Nutrition_and_Management/Spring_2016/6ImpactsofSchedulingRecessBeforeLunch.pdf

United States Department of Agriculture and United Sates Department of Health and Human Services. (2015, Dec.). 2015-2020 dietary guidelines for Americans. $8^{\text {th }}$ edition. Retrieved from https://health.gov/dietaryguidelines/2015/resources/20152020_Dietary_Guidelines.pdf

United States Department of Agriculture: Food and Nutrition Service. (2017a, Aug.). The National School Lunch Program. Retrieved from https://fns-prod.azureedge.net/ sites/default/files/cn/NSLPFactSheet.pdf

United States Department of Agriculture: Food and Nutrition Service. (2017b, Mar. 10). Child nutrition tables. Retrieved from https://www.fns.usda.gov/pd/child-nutrition-tables United States Department of Agriculture: Food and Nutrition Service. (2017c, Feb. 13). School meals: Healthy hunger free kids act. Retrieved from https://www.fns.usda.gov/schoolmeals/healthy-hunger-free-kids-act

United States Department of Agriculture: Food and Nutrition Service. (2016, Aug. 18). National School Lunch Program (NSLP). Retrieved from https://www.fns.usda.gov/nslp/national-school-lunch-program-nslp 
United States Department of Agriculture: Food and Nutrition Service. (2010, Dec. 20).

Healthy Hunger-Free Kids Act: USDA Office of Communications. Retrieved from https://www.fns.usda.gov/tags/healthy-hunger-free-kids-act-0

World Health Organization. (2016, June). Obesity and overweight. Retrieved from http://www.who.int/mediacentre/factsheets/fs311/en/ 


\section{APPENDIX A: TEACHER SURVEY}

\section{Scheduling}

How supportive are you in scheduling....

$\begin{array}{lccccc} & \text { Not Very } & & \text { Very } \\ & \text { Supportive } & & \text { Supportive } \\ \text { Lunch period before recess } & 1 & 2 & 3 & 4 & 5 \\ \text { Lunch period after recess } & 1 & 2 & 3 & 4 & 5\end{array}$

\section{Child Feeding Implications}

How adequate do you feel the following feeding implications are under the current rotation...

\section{Completely}

Inadequate

Consideration of program impact on special needs students

Children's food consumption at lunch

Making sure children get enough to eat/are not hungry

Impact on meal digestion

Meeting children's dietary/nutritional needs

Making sure children have enough time to eat

1

$\begin{array}{lllll}1 & 2 & 3 & 4 & 5 \\ 1 & 2 & 3 & 4 & 5 \\ 1 & 2 & 3 & 4 & 5 \\ 1 & 2 & 3 & 4 & 5\end{array}$

\section{Logistics}

How well defined are the following logistics of the current recess schedule... 


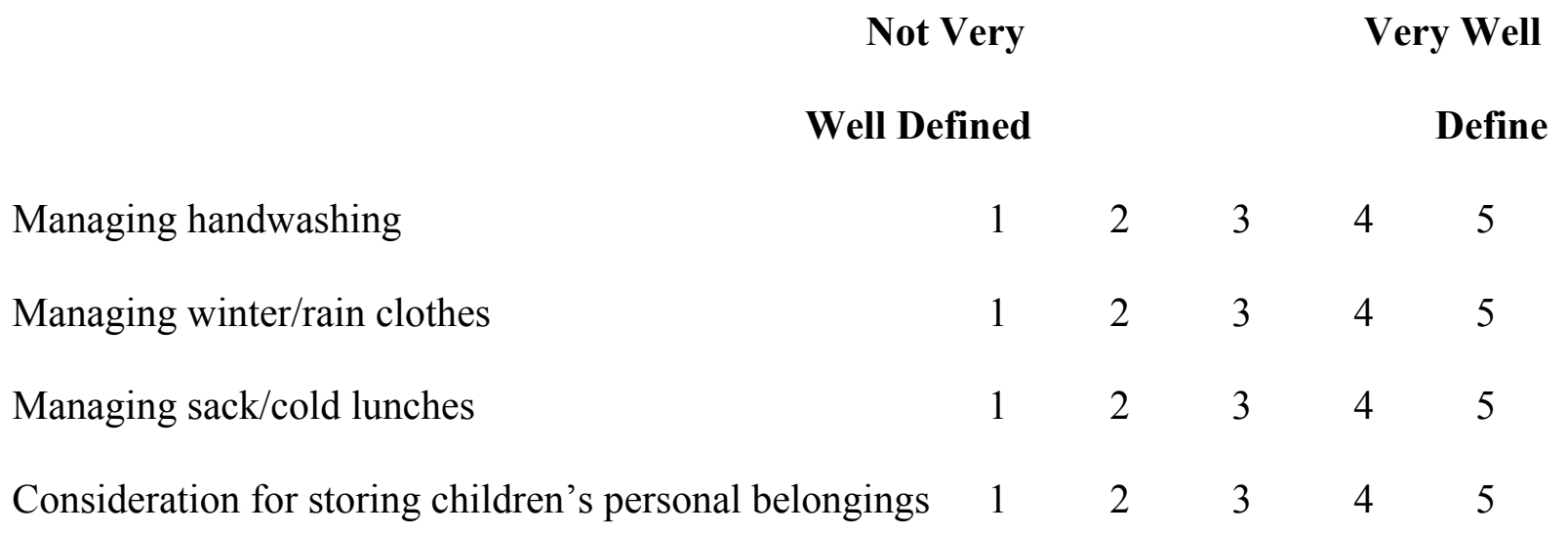

\section{Behavior}

How would you describe the current behavior trends taking into account the current recess schedule...

Very Poor

Children's behavior in the classroom

Children's behavior in the cafeteria

$\begin{array}{lllll}1 & 2 & 3 & 4 & 5 \\ 1 & 2 & 3 & 4 & 5\end{array}$

\section{Academics}

How much do you believe the current placement of recess affects the following measures...

\section{Strongly Disagree}

Placement positively affects student's academic work

Placement negatively affects student's academic work

Placement helps children stay focused in the morning

Placement helps children focus when returning to class

12

2

3

Strongly Agree 


\section{Other Questions:}

What is the greatest barrier faced when recess is after lunch?

What is the greatest barrier faced when recess is before lunch?

Is there anything else you would like to share? 


\section{APPENDIX B: PRINCIPAL AND LUNCHROOM SUPERVISORS INTERVIEW QUESTIONS- RECESS AFTER LUNCH}

- Please share the first thing that comes to mind when you hear the word "recess."

- How do you feel about recess before [after] lunch?

- Are you aware of the research that shows children eat better, waste less food, and behave better with recess scheduled prior to lunch? Can you share your thoughts about this?

- What is the greatest barrier to having recess prior to lunch?

- What is the greatest barrier to having recess after lunch?

- Where did the initial idea for you to change your schedule to recess prior to lunch come from?

- Are there specific issues that affect you in your role regarding recess before [after] lunch?

- Please describe the current behavior trends that occur during lunch time.

- Is there anything we should have talked about but didn't? 


\section{APPENDIX C: PRINCIPAL AND LUNCHROOM SUPERVISORS INTERVIEW QUESTIONS- RECESS BEFORE LUNCH}

- How do you feel about recess before lunch?

- Research shows children eat better, waste less food, and behave better with recess scheduled prior to lunch? Can you share your thoughts about this?

- What is the greatest barrier to having recess prior to lunch?

- What is the greatest barrier to having recess after lunch?

- Are there specific issues that affect you in your role regarding recess before lunch?

- Please describe the current behavior trends that occur during lunch time.

- Which recess timing do you prefer and why?

- Is there anything we should have talked about but didn't? 